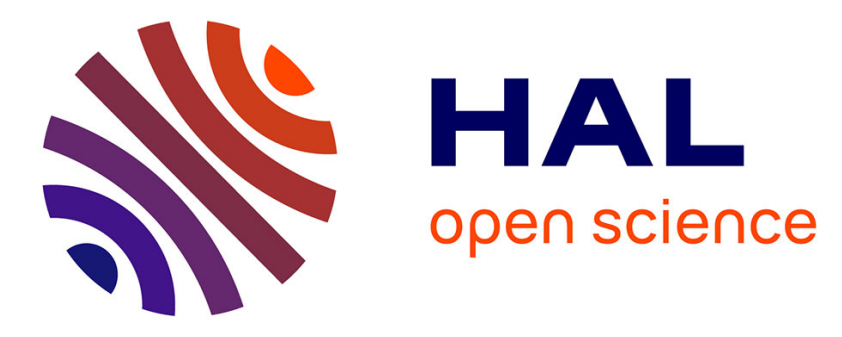

\title{
Significance of serum uric acid in pulmonary hypertension due to systemic sclerosis: a pilot study
}

Theodoros Dimitroulas, Georgios Giannakoulas, Hariklia Dimitroula, Tilemahos Sfetsios, Despina Parcharidou, Haralambos Karvounis, Loukas

Settas

\section{To cite this version:}

Theodoros Dimitroulas, Georgios Giannakoulas, Hariklia Dimitroula, Tilemahos Sfetsios, Despina Parcharidou, et al.. Significance of serum uric acid in pulmonary hypertension due to systemic sclerosis: a pilot study. Rheumatology International, 2010, 31 (2), pp.263-267. 10.1007/s00296-010-1557-4 . hal-00610798

\section{HAL Id: hal-00610798 \\ https://hal.science/hal-00610798}

Submitted on 25 Jul 2011

HAL is a multi-disciplinary open access archive for the deposit and dissemination of scientific research documents, whether they are published or not. The documents may come from teaching and research institutions in France or abroad, or from public or private research centers.
L'archive ouverte pluridisciplinaire HAL, est destinée au dépôt et à la diffusion de documents scientifiques de niveau recherche, publiés ou non, émanant des établissements d'enseignement et de recherche français ou étrangers, des laboratoires publics ou privés. 


\section{Significance of serum uric acid in pulmonary arterial hypertension due to systemic sclerosis: a pilot study}

Theodoros Dimitroulas, $\mathrm{MD}, \mathrm{PhD}^{1}$, Georgios Giannakoulas $\mathrm{MD}, \mathrm{PhD}^{2}$, Hariklia Dimitroula MD, $\mathrm{PhD}^{2}$, Tilemahos Sfetsios MD, $\mathrm{PhD}^{1}$, Despina Parcharidou MD, $\mathrm{PhD}^{2}$, Haralambos Karvounis MD, $\mathrm{PhD}^{2}$, Loukas Settas MD, $\mathrm{PhD}^{1}$

${ }^{1}$ First Department of Internal Medicine, AHEPA University Hospital, Thessaloniki, Greece

${ }^{2}$ Cardiology Department, AHEPA University Hospital, Thessaloniki, Greece

Corresponding author and reprint requests:

Theodoros Dimitroulas, MD, PhD

First Department of Internal Medicine,

AHEPA University Hospital, Stilp. Kiriakidi 1, GR-54637,

Thessaloniki, Greece

Tel: +302310994609

fax: +302310994863

E-mail address: dimitroul@hotmail.com 


\begin{abstract}
Systemic sclerosis (SSc) is a connective tissue disease, which may lead to elevated pulmonary arterial pressure due to pulmonary arterial hypertension and/or left ventricular diastolic dysfunction. Uric acid (UA) has been shown to be elevated in patients with pulmonary hypertension $(\mathrm{PH})$ and heart failure. We aimed to investigate the potent relationship between serum UA and pulmonary pressure as well as functional capacity in patients with SSc. We studied 66 patients (mean age $57.7 \pm 12.1$ years, 63 women), presenting with SSc. Systolic pulmonary artery pressure assessed by echocardiography, lung function tests, six-minute walk test (6MWT) and serum UA levels were recorded in all patients. In $24(36 \%)$ patients the diagnosis of PH was established by echocardiography (systolic pulmonary artery pressure $\geq 40 \mathrm{mmHg}$ ). $\mathrm{PH}$ patients had higher UA serum levels compared to patients without $\mathrm{PH}(5.1 \pm 2.1 \mathrm{mg} / \mathrm{dl}$ vs $4.2 \pm 0.9 \mathrm{mg} / \mathrm{dl}, \mathrm{p}=0.04)$. Amongst $\mathrm{PH}$ patients, UA values were inversely correlated with the SMWT distance $(r=-0.51, p=0.01)$. Serum UA values increased in proportion to the functional capacity $\mathrm{PH}$ in patients with scleroderma. Further investigations in prospective studies will unfold in detail the pathophysiological significance of UA in SSc patients with $\mathrm{PH}$, and determine its role as a prognostic marker in the assessment and monitoring of the disease.
\end{abstract}

Key words: uric acid, systemic sclerosis, pulmonary arterial hypertension, six minute walking test 


\section{Introduction}

Systemic sclerosis $(\mathrm{SSc})$ is a connective tissue disease characterized by excessive collagen deposition in the skin and the internal organs and vascular involvement with generalized disturbance of the microcirculation [1-3]. Systemic sclerosis related pulmonary arterial hypertension (SScPAH) is a serious and devastating complication of the disease affecting $8-15 \%$ of SSc patients [4,5]. Pulmonary hypertension $(\mathrm{PH})$ in these patients may also be caused by left ventricular diastolic dysfunction due to myocardial involvement [6]. The presence of elevated pressure in the pulmonary circulation conveys bad prognosis in this population irrespective of the etiology of $\mathrm{PH}[7]$.

Uric acid (UA) is the final oxidation product of purine metabolism. Serum UA levels have been shown to be elevated in conditions of impaired oxidative metabolism such as chronic heart failure [8], and obstructive pulmonary disease [9]. Elevated UA values have been described in various rheumatic diseases [10] including lupus nephritis [11] and gout [12]. Several studies have demonstrated that increased UA serum concentrations in patients with $\mathrm{PH}$ of various etiologies correlate with the severity and the prognosis of the disease [13-15].

There is very little information available on the clinical significance of UA in SSc patients with PH. Therefore, we hypothesised that 1) uric acid levels are elevated in patients with SSc and $\mathrm{PH}$ and 2) elevated pulmonary pressure are associated to functional capacity in this population. 


\section{Patients and Methods}

\section{Study population}

This study enrolled 66 patients with SSc as defined by the revised ACR [16] criteria who visited our center for follow-up care between February 2007 and February 2008. Patients were selected after exclusion of hypertrophic, dilated or restrictive cardiomyopathy, left ventricular ejection fraction $(\mathrm{LVEF})<55 \%$, any left and right sided valvular disease more than moderate degree severity, symptomatic lower limb vascular disease, severe interstitial lung fibrosis defined as functional volume capacity $(\mathrm{FVC})<60 \%$ of predicted, medical history of hypertension and renal failure determined by serum creatinine levels $>1.2 \mathrm{mg} / \mathrm{dl}$. Smoker patients were also excluded, since smoking has been shown to affect pulmonary function in SSc patients [17]. None of the patients received treatment with diuretics which may affect UA serum levels. All patients were evaluated for cardiac and pulmonary involvement. Exercise capacity was assessed by six minute walking test (6MWT). The study received ethical approval from the scientific committee of the Aristotle University of Thessaloniki and patients provided written informed consent.

\section{Pulmonary function testing}

Pulmonary involvement was assessed by high sensitivity computed tomography. Lung function tests measured FVC, forced expiratory volume in 1 second $\left(\mathrm{FEV}_{1}\right)$, and diffusing capacity for carbon monoxide (DLCO).

\section{Echocardiography}

Complete two-dimensional and Doppler echocardiographic examinations were performed in all patients at the same day of the UA evaluation. We used a 
commercially available system (Vivid 7, Vingmed, GE, Norway). From the apical 4chamber view, RV inflow view, and parasternal short axis or subcostal view, continuous-wave Doppler echocardiography was used to assess the peak tricuspid regurgitant velocity [18]. Systolic pulmonary artery pressure was estimated by calculating the maximal velocity of the tricuspid regurgitant jet and then, further using the Bernoulli equation, adding to this value an estimated right atrial pressure based on both the size of the inferior vena cava and the change in diameter of this vessel during respiration [19]. PH was considered present when the systolic pulmonary artery pressure value $\geq 40 \mathrm{mmHg}[20]$.

\section{Exercise capacity}

The 6MWT was performed using a standardized protocol in accordance to guidelines in the American Thoracic Society statement 2002 [21]. Patients walked unassisted an enclosed-level corridor; length to first turn around was 30 metres. All patients were told to use their own pace, but to cover as much ground as possible in 6 $\min$.

\section{Blood sampling for UA measurement}

For the measurement of the serum UA, creatinine, triglyceride, total cholesterol, ESR and CRP levels, venous blood sample was drawn after an overnight fast, at the study entry. Serum UA levels were determined in close temporal automated chemistry analysers. This test is a colometric assay based on the oxidation of UA by the specific enzyme uricase. 


\section{Statistical analysis}

Variables are presented as mean \pm S.D, except from the duration of the disease, which is expressed as median [25th-75th percentile]. UA and 6MWT values were normally distributed (Kolmogorov-Smirnov and P-P plot). Categorical data are presented as absolute value, and comparisons were tested by Fisher's exact test. Clinical and biological characteristics between the two groups of SSc patients were compared using the Student's t-test. The relationship between UA and patient's functional state as measured by the 6MWT and other laboratory or functional pulmonary indices was assessed by the Pearson's correlation coefficient. A value of $\mathrm{P}<0.05$ was considered significant. Statistical analysis was performed using SPSS 13 for Windows (SPSS Inc., Chicago, USA).

\section{Results}

In $24(36 \%)$ patients the diagnosis of PH was established (22 females, mean age $60 \pm 10$ years; 19 with limited cutaneous and 6 with diffuse cutaneous SSc). The clinical and biologic characteristics of SSc patients with and without elevated pulmonary pressure are summarized in Table 1 .

SSc patients with $\mathrm{PH}$ had higher UA values $(5.1 \pm 2.1 \mathrm{mg} / \mathrm{dl})$ compared to patients with normal pulmonary pressure $(4.2 \pm 0.9 \mathrm{mg} / \mathrm{dl}, \mathrm{p}=0.04)$ (Figure 1). Amongst PH patients, UA values were inversely correlated with the SMWT distance $(\mathrm{r}=-0.51, \mathrm{p}=0.01)$ (Figure 2). No significant correlations were found between UA and serum creatinine, FVC, FEV 1 and DLCO values in the same population. Moreover, UA was not related with sex, subtype of the disease, autoantibodies and the clinical features of the disease. In the subgroup of patients without $\mathrm{PH}$, no correlation between UA levels and exercise capacity as assessed by the 6MWT was detected. 


\section{Discussion}

The mechanisms responsible for the elevated serum UA concentrations in SSc patients with PH may be multifactorial. Increased UA levels have been suggested to reflect raised xanthine oxidase activity - an important source of oxygen free radicals in patients with heart failure [22]. The latter provides a pathophysiological link of UA with a variety of detrimental processes, including increased cytokine production, inflammation and endothelial dysfunction, which are considered to be among the primary events during the progression of the scleroderma induced vasculopathy and fibrosis. Superoxide dismutase represents the major antioxidant defense system against oxygen free radicals. Elevated levels of UA are correlated with decreased superoxide dismutase activity in patients with chronic heart failure [23]. A recent study showed diminished superoxide dismutase activity in SSc patients [24], which also supports the hypothesis that oxidative stress has an important role in the progression of vascular disease, leading to an increase in UA levels in SSc patients with PH.

In the current study we demonstrated inverse correlation between UA levels and functional status in patients with $\mathrm{PH}$. The 6MWT is commonly used for the objective assessment of functional capacity and is used in the evaluation, management, and follow-up of patients with PH [21]. As SSc patients usually present with cutaneous leg ulcers or pulmonary interstitial involvement that may invalidate the 6MWT, we excluded patients with the aforementioned clinical entities. UA concentration has emerged as a significant predictor of cardiopulmonary exercise parameters and measures of diminished functional capacity in patients with chronic heart failure $[25,26]$. 
Measurement of serum UA levels is simple, inexpensive and routinely available. Although other biochemical markers including brain natriuretic peptide [2730], asymmetric dimethylarginine [31] and vascular endothelial growth factor [32] have been proposed as biochemical markers for the detection of PH in SSc, UA may also serve as an additional indicator for the assessment of exercise capacity in this population.

The findings have to be considered against the background of the limits of the study. This is a pilot single centre cross-sectional study and it is limited by the lack of a controlled healthy population. The small number of patients may have contributed to the borderline difference of UA and SMWT values noticed between the two groups of patients (with and without PH). Another important point is the fact that the patients did not undergo right heart catheterization and the lack of correlation between UA levels and hemodynamic indices. Additionally, UA levels are dependent on age and sex, and are affected by the renal impairment and diuretic therapy; hence their interpretation may be difficult in some patients. We took particular care to exclude patients under diuretics, but additional investigations in larger cohorts of patients are warranted to confirm the findings of the present study.

In conclusion, we established that serum UA values increase in proportion to the clinical severity of $\mathrm{PH}$ in patients with SSc. Further investigations in prospective studies will unfold in detail the pathophysiological significance of UA in PH in this group, and determine its role as a biochemical marker in the assessment and monitoring of the disease. 
The authors have to declare no conflicts of interest.

\section{Acknowledgements}

Dr Giannakoulas has received funding from the Hellenic Atherosclerosis Society. 


\section{REFERENCES}

1. Teh CL, Kuan YC, Wong JS (2009) Systemic sclerosis in Sarawak: a profile of patients treated in the Sarawak General Hospital. Rheumatol Int 29:1243-5

2. Toya SP, Tzelepis GE (2009) The many faces of scleroderma sine scleroderma: a literature review focusing on cardiopulmonary complications. Rheumatol Int 29:861-8

3. Rosato E, Maione S, Vitarelli A, et al (2009) Regional diastolic function by tissue Doppler echocardiography in systemic sclerosis: correlation with clinical variables. Rheumatol Int 29:913-9

4. Hachulla E, Gressin V, Guillevin L, et al (2005) Early detection of pulmonary arterial hypertension in systemic sclerosis: a French nationwide prospective multicenter study. Arthritis Rheum 52:3792-800

5. Mukerjee D, St George D, Coleiro B, et al (2003) Prevalence and outcome in systemic sclerosis associated pulmonary arterial hypertension: application of a registry approach. Ann Rheum Dis 62:1088-93

6. Hachulla E, de Groote P, Gressin V, et al (2009) Itinér AIR-Sclérodermie Study Group. The three-year incidence of pulmonary arterial hypertension associated with systemic sclerosis in a multicenter nationwide longitudinal study in France. Arthritis Rheum 60:1831-9

7. Steen VD, Medsger TA (2007) Changes in causes of death in systemic sclerosis, 1972-2002. Ann Rheum Dis 66:940-4

8. Leyva F, Anker S, Swan JW, et al (1997) Serum uric acid as an index of impaired oxidative metabolism in chronic heart failure. Eur Heart J 18:858-65

9. Braghiroli A, Sacco C, Erbetta M, Ruga V, Donner CF (1993) Overnight urinary uric acid: creatinine ratio for detection of sleep hypoxemia. Validation 
study in chronic obstructive pulmonary disease and obstructive sleep apnea before and after treatment with nasal continuous positive airway pressure. Am Rev Respir Dis 148:173-8

10. Sari I, Akar S, Pakoz B (2009) Hyperuricemia and its related factors in an urban population, Izmir, Turkey. Rheumatol Int. 29:869-74

11. Yang Z, Liang Y, Xi W, et al (2010) Association of serum uric acid with lupus nephritis in systemic lupus erythematosus. Rheumatol Int (In press)

12. De Leonardis F, Govoni M, Colina M, et al (2007) Elderly-onset gout: a review. Rheumatol Int 28:1-6

13. Nagaya N, Uematsu M, Satoh T, et al (1999) Serum uric acid levels correlate with the severity and the mortality of primary pulmonary hypertension. Am $\mathbf{J}$ Respir Crit Care Med 160:487-92

14. Bendayan D, Shitrit D, Ygla M, Huerta M, Fink G, Kramer MR (2003) Hyperuricemia as a prognostic factor in pulmonary arterial hypertension. Respir Med 97:130-3

15. Voelkel MA, Wynne KM, Badesch DB, Groves BM, Voelkel NF (2000) Hyperuricemia in severe pulmonary hypertension. Chest 117:19-24

16. Subcommittee for Scleroderma Criteria of the American Rheumatism Association Diagnostic and Therapeutic Criteria Committee (1980) Preliminary criteria ror the classification of the systemic sclerosis (scleroderma). Arthritis Rheum 23:581-90

17. Quadrelli SA, Molinari L, Ciallella LM, et al (2009) Patterns of pulmonary function in smoking and nonsmoking patients with progressive systemic sclerosis. Rheumatol Int 29:995-9 
18. Currie P, Seward J, Reeder G (1985) Continuous-wave Doppler echocardiographic assessment of severity of calcific aortic stenosis: a simultaneous Doppler-catheter correlative study in 100 adult patients. Circulation 71:1162-1169

19. Nagueh S, Kopelen H, Zoghbi W (1996) Relation of mean right atrial pressure to echocardiographic and Doppler parameters of right atrial and right ventricular function. Circulation 93:1160-1169

20. Mukerjee D, St George D, Knight C, et al (2004) Echocardiography and pulmonary function as screening tests for pulmonary arterialhypertension in systemic sclerosis. Rheumatology 43:461-6

21. ATS Committee on Proficiency Standards for Clinical Pulmonary Function Laboratories. ATS statement: guidelines for the six-minute walk test. (2002) Am J Respir Crit Care Med 166:111-7

22. Leyva F, Anker SD, Godsland IF, et al (1998) Uric acid in chronic heart failure: a marker of chronic inflammation. Eur Heart J 19:1814-22

23. Alcaino H, Greig D, Chiong M, et al (2008) Serum uric acid correlates with extracellular superoxide dismutase activity in patients with chronic heart failure. Eur J Heart Fail 10:646-51

24. Frent-Cornateanu R, Mihai C, Stoian I, Lixandru D, Bara C, Moldoveanu E (2008) Antioxidant defense capacity in scleroderma patients. Clin Chem Lab Med 46:836-41

25. Leyva F, Anker S, Swan JW, et al (1997) Serum uric acid as an index of impaired oxidative metabolism in chronic heart failure. Eur Heart J 18:858-65 
26. Bergamini C, Cicoira M, Rossi A, Vassanelli C (2009) Oxidative stress and hyperuricaemia: pathophysiology, clinical relevance, and therapeutic implications in chronic heart failure. Eur J Heart Fail 11:444-52

27. Dimitroulas T, Giannakoulas G, Karvounis H, Gatzoulis MA, Settas L (2010) Natriuretic peptides in systemic sclerosis-related pulmonary arterial hypertension. Semin Arthritis Rheum 39:278-84

28. Mukerjee D, Yap LB, Holmes AM, et al (2003) Significance of plasma Nterminal pro-brain natriuretic peptide in patients with systemic sclerosisrelated pulmonary arterial hypertension. Respir Med 97:1230-6

29. Allanore Y, Borderie D, Meune C, et al (2003) N-terminal pro-brain natriuretic peptide as a diagnostic marker of early pulmonary artery hypertension in patients with systemic sclerosis and effects of calcium-channel blockers. Arthritis Rheum 48:3503-8

30. Dimitroulas T, Giannakoulas G, Karvounis H, et al (2007) Neurohormonal activation in patients with systemic sclerosis-related pulmonary arterial hypertension. Int J Cardiol 121:135-7

31. Dimitroulas T, Giannakoulas G, Sfetsios T, et al (2008) Asymmetrical dimethylarginine in systemic sclerosis-related pulmonary arterial hypertension. Rheumatology 47:1682-5

32. Papaioannou AI, Zakynthinos E, Kostikas K, et al (2009) et al Serum VEGF levels are related to the presence of pulmonary arterial hypertension in systemic sclerosis. BMC Pulm Med 9:18 


\section{TABLES}

Table 1 : Clinical and biochemical data of SSc patients

\begin{tabular}{|c|c|c|c|c|}
\hline & $\begin{array}{l}\text { All SSc patients } \\
(n=66)\end{array}$ & $\begin{array}{c}\text { SSc patients without } \\
\text { PH }(\mathrm{n}=42)\end{array}$ & $\begin{array}{c}\text { SSc patients with } \\
\text { PH }(\mathrm{n}=24)\end{array}$ & $\mathrm{p}$ \\
\hline Age (years) & $57.7 \pm 12.1$ & $55.3 \pm 13.1$ & $60 \pm 10$ & NS \\
\hline Females/Males & $61 / 3$ & $41 / 1$ & $22 / 2$ & NS \\
\hline Duration of the disease (years) & $10[0.2-31]$ & $9.7[0.2-31]$ & $11[2-25]$ & NS \\
\hline Limited/Diffuse SSc & $47 / 19$ & $28 / 14$ & $19 / 5$ & NS \\
\hline Raynaud's & $47(71.2 \%)$ & $30(71.4 \%)$ & $17(70 \%)$ & NS \\
\hline FVC (\% predicted $)$ & $86.8 \pm 22.6$ & $88 \pm 25.4$ & $83 \pm 18$ & NS \\
\hline $\mathrm{FEV}_{1}(\%$ predicted $)$ & $89.4 \pm 23.9$ & $89.8 \pm 26.8$ & $88 \pm 20$ & NS \\
\hline DLCO (\% predicted) & $65.1 \pm 22.1$ & $65 \pm 22$ & $62 \pm 21$ & NS \\
\hline $\mathrm{EF}(\%)$ & $65.5 \pm 4.2$ & $65.5 \pm 4.4$ & $65.5 \pm 4.8$ & NS \\
\hline Creatinine $(\mathrm{mg} / \mathrm{dl})$ & $0.73 \pm 0.1$ & $0.8 \pm 0.1$ & $0.73 \pm 0.1$ & NS \\
\hline ESR & $32.3 \pm 2$ & $30.5 \pm 21$ & $34.5 \pm 20$ & NS \\
\hline $\mathrm{CRP}(\mathrm{mg} / \mathrm{ml})$ & $0.46 \pm 0.1$ & $0.5 \pm 0.3$ & $0.4 \pm 0.2$ & NS \\
\hline ANA & $58(87.3 \%)$ & $37(88.1 \%)$ & $19(79.1 \%)$ & NS \\
\hline SCL-70 & $21(31.8 \%)$ & $13(30.9 \%)$ & $9(37.5 \%)$ & NS \\
\hline $\mathrm{ACA}$ & $18(27.2 \%)$ & $10(23.8 \%)$ & $8(33.3 \%)$ & NS \\
\hline Uric Acid (mg/dl) & $4.68 \pm 1.84$ & $4.27 \pm 0.98$ & $5.14 \pm 2.18$ & 0.04 \\
\hline 6MWT (metres) & $405.4 \pm 106.4$ & $423 \pm 98$ & $383 \pm 113$ & 0.04 \\
\hline
\end{tabular}

Categorical data are presented as absolute value (percentages).

FVC: forced vital capacity, $\mathrm{FEV}_{1}$ : forced expiratory volume in 1 second, DLCO: diffusing capacity for carbon monoxide, EF: ejection fraction of left ventricular, sPAP: systolic pulmonary artery pressure, Cre: 
serum creatinine, ESR: erythrocyte sedimentation rate, CRP: C-reactive protein, ANA: antinuclear antibodies, Scl-70 : anti-topoisomerase I antibodies, ACA: anticentromere antibodies, 6MWT: six-minute walk test 


\section{Figure 1:}

Boxplot showing serum values of UA, with boxes indicating the mean and the 25 th- 75 th percentile in $\mathrm{PH}$ patients compared with SSc patients without $\mathrm{PH}$.

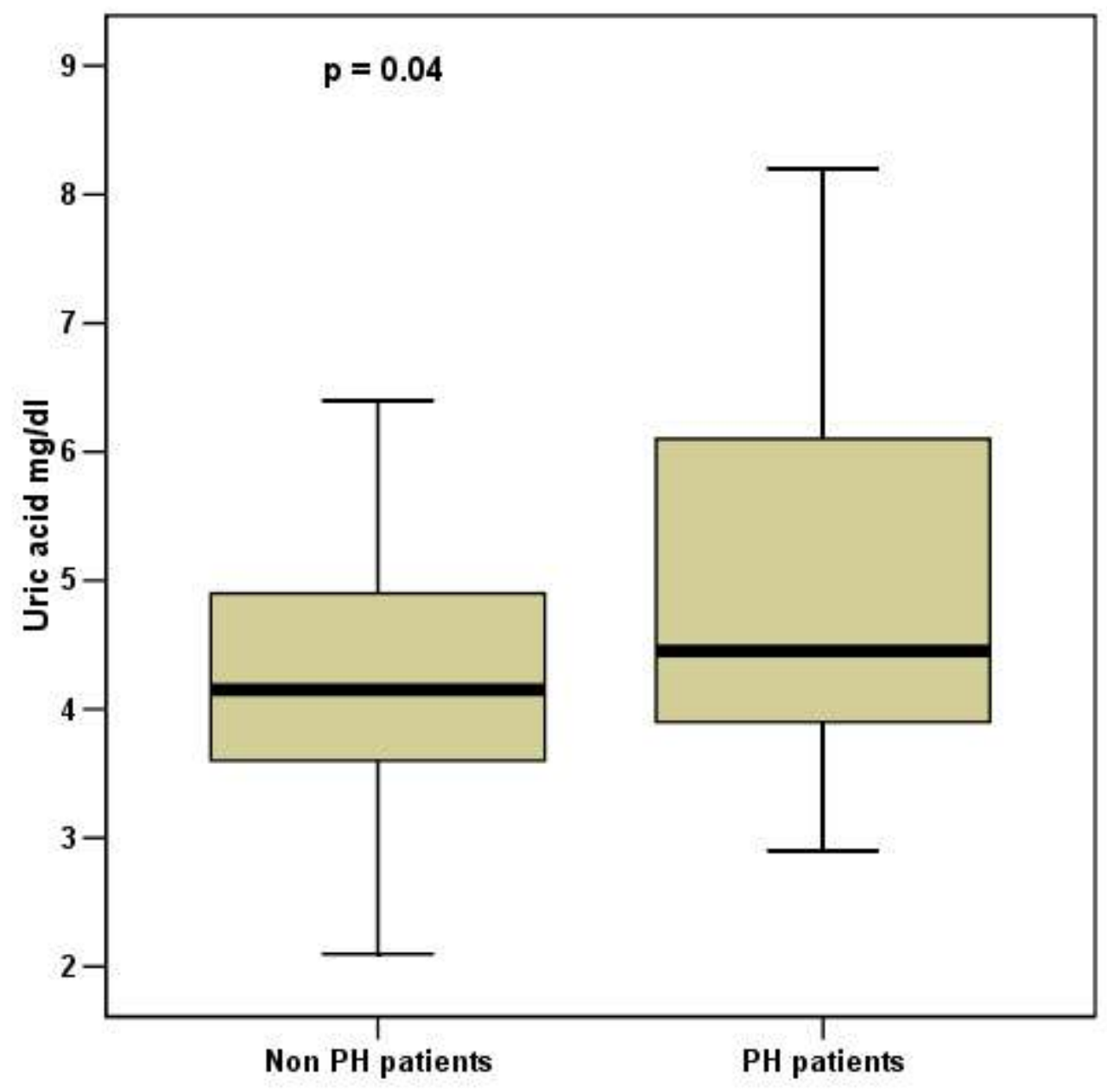




\section{Figure 2:}

Correlation between UA serum values and 6MWT in PH patients

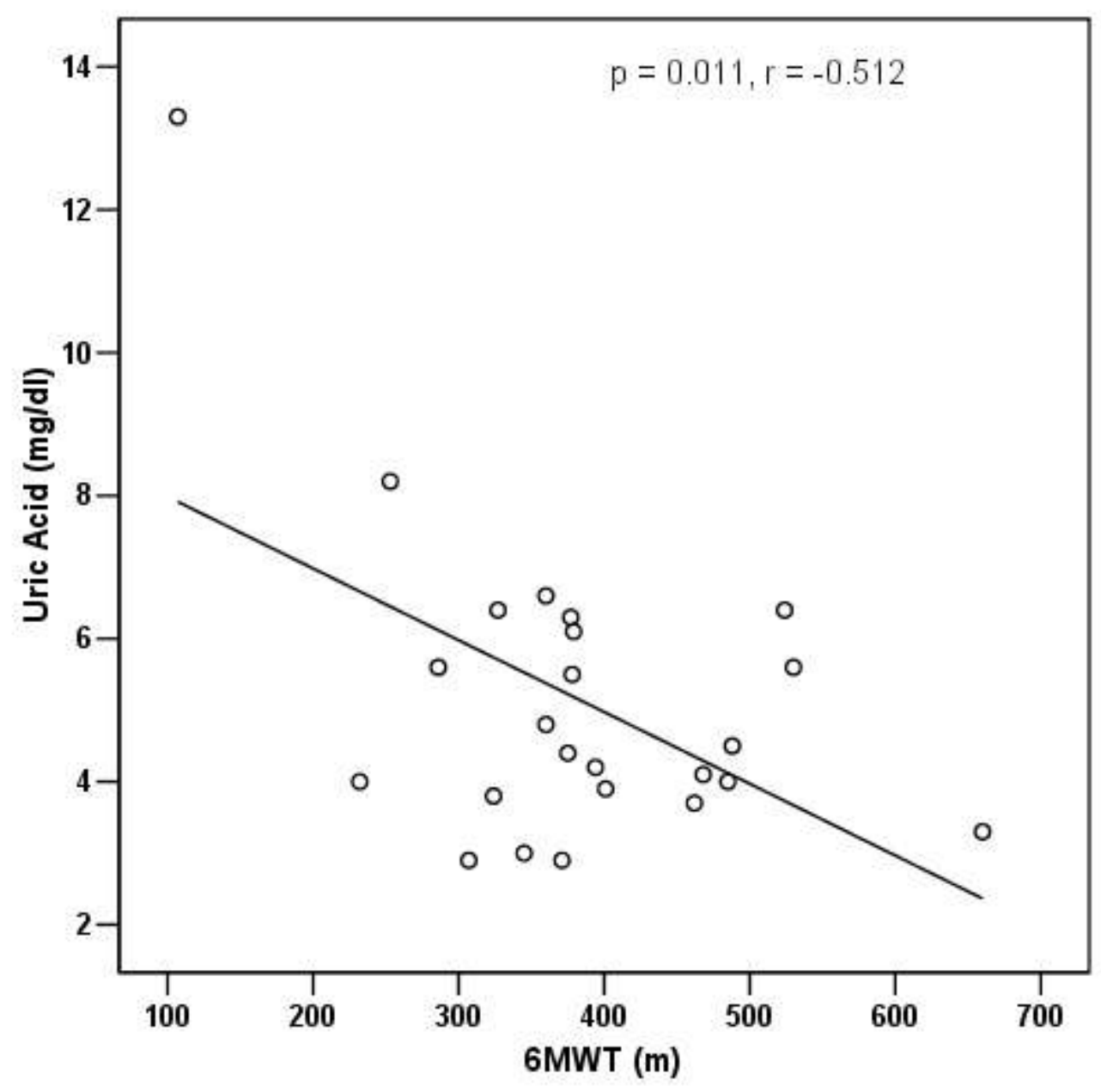

